\title{
ESTRATÉGIAS COMPETITIVAS NA INDÚSTRIA ELETRÔNICA BRASILEIRA E CHINESA: UMA MENSURAÇÃO A PARTIR DA ABORDAGEM DO DIAMANTE DUPLO GENERALIZADO
}

\author{
Stela Luiza de Mattos Ansanelli \\ Conrado de Castro Oliveira
}

\section{RESUMO}

A indústria eletrônica é essencial para impulsionar o desenvolvimento econômico, por incorporar valor agregado, aumentar a eficiência e produtividade e estar na base de quase todos os setores da economia. Nas últimas décadas, a China tem se destacado como principal ofertante no mercado mundial do setor, enquanto no Brasil existem sérias fragilidades competitivas. Contribuindo para a discussão sobre a direção que o setor deveria seguir, o objetivo deste trabalho é mensurar a competitividade da indústria eletrônica nesses dois países e estimar qual é a melhor estratégia competitiva para a indústria brasileira, tomando como referência a chinesa. Por meio do modelo do diamante duplo generalizado, verificou-se que a competitividade internacional do setor na China é bastante elevada, mas no Brasil depende de variáveis domésticas. A melhor estratégia para o complexo eletrônico nacional é a diferenciação, pois resultaria em um aumento de $4 \%$ na sua competitividade em um mercado de trilhões de dólares.

PALAVRAS-CHAVE: Estratégia competitiva; indústria eletrônica; Brasil; China.

\section{Competitive Strategies in the Electronics Industry in Brazil and China: a measure under the generalized double diamond approach}

\begin{abstract}
The electronics industry is essential to stimulate economic development; because it incorporates aggregated value, increases efficiency and productivity, and is present in almost all sectors of the economy. In the last decades, China has stood out as the main provider in the worldwide market of the sector, while in Brazil there are still serious competitive fragilities. In order to contribute to the discussion about the direction the sector should take, the objective of this paper is to measure the competitiveness of the electronics industry in both countries and to estimate what is the best competitive strategy for Brazil in relation to China. Through the generalized double diamond model, it was verified that the international competitiveness of China is very strong, but in Brazil the competitiveness depends heavily on domestic variables. The best strategy for the national electronics industry is a differentiation strategy, because it would result in an increase of $4 \%$ in its competitiveness in a trillion-dollar market.
\end{abstract}

KEYWORDS: Competitive Strategy; Electronics Industry; Brazil; China.

Classificação JEL: L10

\section{Introdução}

A indústria eletrônica é essencial para impulsionar o desenvolvimento de diversos setores da economia de um país, pois se encontra na base de quase todas as atividades, é autora de mudanças e de processos industriais e é responsável pelo aumento da produtividade do trabalho. Entre 1996 e 2006, o crescimento médio do setor foi de $7 \%$ ao ano, superior ao das indústrias aeroespacial, farmacêutica e automotiva e ao do Produto Interno Bruto (PIB) mundial, que foi da ordem de $3 \%$ ao ano. $\mathrm{O}$ valor de mercado global foi estimado em $€ 1,136$ trilhão em 2008 , dos quais $20 \%$ equivale à receita dos montadores terceirizados (GUTIERREZ, 2010). 
Neste contexto, os países asiáticos se destacaram com êxito na implantação do setor, sobretudo Coreia do Sul, Taiwan e, recentemente, China. No mercado mundial, a presença chinesa tem crescido sobremaneira, uma vez que a participação das exportações no total mundial passou de 14\% em 2002 para 37\% em 2014. O país é o maior ofertante global, pois 26\% das empresas localizavam-se na China em 2008. O crescimento dos fabricantes está em cerca de $15 \%$ ao ano (COMTRADE, s/d; GUTIERREZ, 2010). Desta forma, torna-se evidente a grandeza competitiva da indústria chinesa em nível internacional.

O Brasil é um grande mercado consumidor e também é considerado um produtor razoável, cuja participação na produção mundial foi de 2,3\% em 2005. No entanto, o setor no país tem apresentado uma série de fragilidades competitivas, tanto na produção interna como nos fluxos de comércio. A contribuição do setor para o PIB encontra-se em torno de 3\% desde 2000 e, no último ano, houve queda do investimento em $10 \%$, da produção física em $20 \%$ e do emprego direto em 37 mil trabalhadores. A deficiência estrutural do setor é grave a ponto de se alertar para o risco de desindustrialização e possível extinção do segmento de componentes, que mais incorpora valor agregado (ABINEE, 2015; DECISION, 2009).

Em termos comerciais, a indústria no Brasil amarga déficits estruturais há muitos anos (hoje em torno de 30 bilhões de dólares) e isso se torna um fator ainda mais alarmante em contextos de crise, quando é necessário melhorar o saldo comercial do país. Entre 2002 e 2014, a participação das exportações brasileiras no mundo, que já é baixa, caiu de 0,35\% para 0,20\%. Mesmo com a aplicação de diversas políticas voltadas à indústria eletrônica, o desempenho se encontra muito aquém do esperado (ABINEE, 2015).

Portanto, enquanto a China é o principal caso de sucesso na produção e comercialização de eletrônicos, no Brasil, o setor está ameaçado e exige ações voltadas a avanços competitivos. Contribuindo para esta problemática, o objetivo deste trabalho é mensurar a competitividade da indústria eletrônica nacional e chinesa, bem como estimar qual estratégia competitiva é a mais indicada para a indústria eletrônica brasileira, tendo como referência a chinesa. Para tanto, será utilizado um modelo de análise chamado de Diamante Duplo Generalizado, avanço teórico do modelo de mensuração de competitividade de Porter (1990), construído a partir da elaboração de 18 indicadores nacionais, setoriais e internacionais. Esse método também oferece uma análise relativa, ou seja, uma comparação com o setor de outro país, no caso a China, pela sua importância na economia mundial e, especificamente, dentro da indústria eletrônica.

\section{Competitividade: situando o debate}

Estratégia competitiva é um assunto intimamente interligado ao padrão de concorrência e tem como objetivo final gerar vantagens competitivas a longo prazo, que aumentarão a competitividade da firma, indústria ou nação. No entanto, o conceito de competitividade é complexo e ainda sem uma definição consensual.

Existem tantas variações e enfoques diferentes que a maioria dos trabalhos se inicia justificando a definição de competitividade que será adotada. Dessa forma, nas últimas décadas, observou-se uma tendência de associar o estudo da competitividade a um conjunto de indicadores, ao invés de tentar desenvolver um arcabouço teórico. De um lado se reconhece que a simples redução a um conjunto de indicadores limita a compreensão do fenômeno da competitividade e quase o faz parecer algo estático, quando na verdade é muito dinâmico (KUPFER, 1992).

De outro, isso não quer dizer que indicadores não possuam espaço na teoria e possam tornarse um instrumento útil. Tomando parâmetros básicos que os indicadores devem cumprir, pode-se organizar os conceitos de competitividade em dois grupos: (1) competitividade como desempenho e (2) competitividade como eficiência. No primeiro grupo, a competitividade é expressa pela participação no mercado, conquistada por alguma firma em um dado período. O principal indicador dessa análise é a participação de um bem no total de exportação, seja de uma firma ou da indústria (KUPFER, 1992; POSSAS, 1999). 
A segunda vertente tenta interpretar a competitividade como a capacidade de uma firma maximizar o rendimento da conversão de insumos em produtos. A firma mais competitiva será a que produzir de maneira mais eficiente no que se refere às tecnologias utilizadas, preços, custos e qualidade. A principal diferença entre essas duas visões é que, na primeira, é a demanda do mercado que define quais firmas são competitivas por meio da seleção de qual produto (e de qual empresa) é comprado. Já na segunda, é a empresa que, ao definir seu modus operandi de acordo com suas restrições tecnológicas, de custo etc., determina sua competitividade.

Quem enxerga a competitividade como desempenho a considera um fenômeno ex-post, ou seja, o resultado de um conjunto de fatores, que inclui, mas não se limita, à eficiência técnica. Por vezes alguns desses fatores são tácitos, como a capacidade de inovação da empresa. Em contrapartida, quem acredita que a competitividade está associada à eficiência crê que seja um fenômeno ex-ante. Significa que "é um grau de capacitação detido pelas firmas, que se traduz nas técnicas por elas praticadas” (KUPFER, 1992, p.3).

Há outras contribuições na adoção da concepção ex-post e ex-ante. Com relação ao primeiro grupo, entende-se que as estratégias buscam a valorização do capital e a competitividade deve refletir a capacidade de auferir lucros ou ganhar espaço no mercado. Logo, são sugeridos indicadores como taxas de lucro obtidas sobre o capital ou a variação da valorização do capital. Já para indicadores ex-ante, essa mensuração torna-se mais difícil, pois depende de perspectivas passadas e futuras. Nesse sentido, propõe-se a criação de um vetor incluindo diversos elementos de dimensões concorrenciais e vantagens detidas pelas firmas. Porém, a validade desse vetor seria extremamente mutável com o tempo (POSSAS, 1999).

Assim, não somente o conceito como também a definição de indicadores de competitividade é um tema rico em termos de discussão e um espaço aberto para novas abordagens.

\subsection{Análise da Competitividade: os modelos de Diamante}

Os modelos de mensuração da competitividade desenvolvidos por Porter (1990) e aprimorados por Cho e Moon (2013), conforme a realidade dos países em desenvolvimento, constituem uma contribuição significativa para a discussão dos indicadores de competitividade.

Buscando entender quais são os principais determinantes do sucesso nacional em certas indústrias, após anos de estudos empíricos e por meio de uma abordagem ex-post, Porter (1990) trouxe contribuições significativas na análise da competitividade. $\mathrm{O}$ autor desenvolveu um modelo para explicar as vantagens competitivas que permite comparar a posição competitiva da nação no contexto global. Esse modelo ficou conhecido, por seu formato, como o Diamante de Porter, conforme se verifica na Figura 1 abaixo.

FIGURA 1: O Diamante de Porter

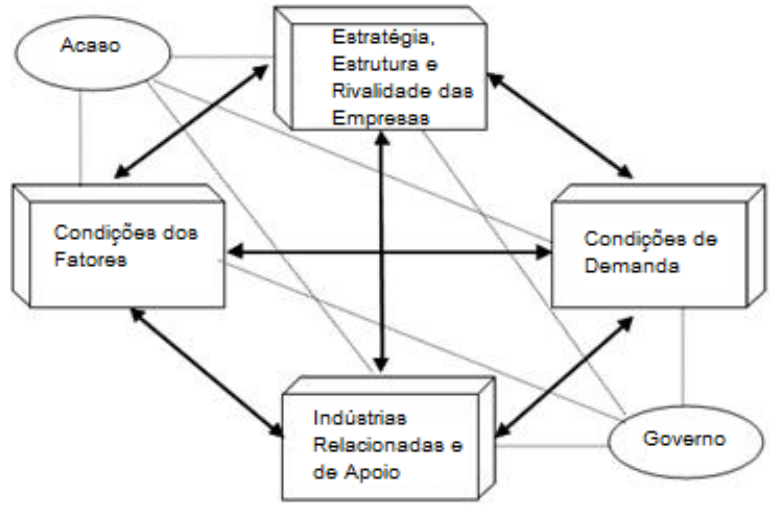

Fonte: Porter (1990) 
A vantagem competitiva é resultado de quatro determinantes fundamentais que modelam a indústria e estimulam, ou não, a criação de vantagens competitivas. São elas: condições dos fatores; condições de demanda; indústrias relacionadas e de apoio e estratégia, estrutura e rivalidade entre firmas. Como podemos ver na Figura 1, os fatores são interligados de modo que um determinante potencializa o outro, seja para maior ou menor competitividade.

As condições dos fatores, primeiro elemento, se referem aos insumos necessários para competir em qualquer indústria que podem ser agrupados em recursos humanos, recursos físicos, estoque de conhecimento, disponibilidade de capital e infraestrutura. A proporção dos fatores utilizados varia conforme a indústria, mas uma boa condição dos fatores e o modo como são utilizados se reflete em vantagem competitiva significativa em termos de qualidade ou de custo (PORTER, 1990).

É necessário distinguir os fatores entre básicos e avançados para qualificar seu impacto sobre as vantagens competitivas. Os fatores básicos são típicos de indústrias extrativistas ou agrícolas e os avançados, de indústrias de ponta. Os últimos são mais importantes para a criação de vantagens competitivas, porque permitem que firmas consigam criar e sustentar as vantagens novas de forma mais rápida e eficiente. Poucos fatores são herdados por um país, eles precisam ser desenvolvidos e criados ao longo do tempo e demandam altos investimentos em recursos humanos e físicos. Esse é o principal motivo pelo qual os fatores avançados são relativamente escassos (PORTER, 1990).

Quanto ao segundo aspecto, as condições de demanda são fundamentais por influenciar a velocidade com que melhorias e inovações são implementadas. Esse fator depende da composição da demanda doméstica, do tamanho e do crescimento do mercado doméstico e dos mecanismos que transferem as preferências domésticas para os estrangeiros. A composição da demanda doméstica determina como as firmas entendem o mercado e depende da natureza dos compradores. Nesse aspecto, a qualidade é mais importante do que a quantidade. O tamanho do mercado doméstico e seu crescimento são relevantes na geração de vantagens competitivas, pois proporcionam economias de escala, estimulando o investimento em grandes fábricas e tecnologia. Embora a integração do comércio internacional tenha diminuído a importância do mercado doméstico, ele ainda é relevante. Por sua vez, os mecanismos que transferem as preferências dos consumidores domésticos para outros países fomentam a demanda por produtos nacionais, contribuindo para o aumento das vendas e criando uma percepção de produto diferenciado ou superior (PORTER, 1990).

Com relação ao terceiro fator, as indústrias de apoio são aquelas necessárias à produção do bem ou serviço específico, como as que vendem insumos ou prestam serviços de logística. Se os fornecedores, por exemplo, possuem vantagens competitivas, elas podem ser transmitidas para a indústria compradora. Já as indústrias relacionadas são as que compartilham atividades em sua cadeia de valor ou que oferecem produtos complementares, como computadores e softwares, por exemplo. Assim, a existência de vantagens em uma indústria pode potencializar a produtividade ou lucros de uma relacionada.

Por fim, estratégia, estrutura e rivalidade entre firmas se referem ao contexto no qual as empresas são criadas e a natureza da competição enfrentada por elas. As estratégias empresariais, aliadas aos objetivos individuais dos gerentes e à cultura de um país, influenciam fortemente a cultura empresarial e, por consequência, a organização das indústrias. Por exemplo, firmas bemsucedidas alemãs, japonesas ou italianas apresentam características específicas daqueles países na organização e no comportamento das firmas (PORTER, 1990).

É importante notar que existe uma associação muito forte entre concorrência doméstica e vantagens competitivas persistentes. A concorrência doméstica é mais eficaz que a estrangeira para o autor, porque a pressão para melhorar está mais perto da realidade das firmas e a transmissão de inovações ocorre de maneira mais rápida. Outro benefício da forte concorrência interna é que ela, geralmente, fortalece e prepara as firmas nacionais para competirem com muito mais força no mercado externo (PORTER, 1990). 
Além desses quatro determinantes, existem mais dois fatores exógenos ao modelo, o acaso e o governo. $\mathrm{O}$ acaso se refere às situações históricas que podem influenciar as vantagens competitivas, como uma invenção extraordinária acidental, decisões políticas de outros países ou guerras. O governo, por sua vez, atua como um fator que afeta todos os determinantes e também é afetado por eles.

Esse arcabouço teórico tornou possível analisar a competitividade em uma nação, região ou setor, mas o modelo tem recebido críticas importantes. O diamante é pouco útil na análise de países em desenvolvimento, pois não considera a importância de empresas multinacionais, tampouco os fluxos de Investimento Direto Estrangeiro (IDE). Muitos países em desenvolvimento adotaram a estratégia de se industrializar atraindo filiais de empresas multinacionais, que influenciam a economia local e a inserção internacional do país. Além disso, com a tendência de integração da economia mundial, a importância de variáveis internacionais tende a superar as domésticas como determinantes da competitividade. Dessa forma, essa ausência pode gerar distorções nas análises.

O modelo do Diamante Duplo Generalizado nasceu dessa crítica. Foi concebido por Rugman e D’Cruz (1993), aprimorado por Moon, Rugman e Verbeke (1998) e aplicado na prática por Cho e Moon (2013). A principal diferença com o modelo de Porter (1990) é que este incorpora o IDE à sua análise e, como as atividades de empresas multinacionais afetam o diamante inteiro, os autores optaram por duplicá-lo ao invés de incluir variáveis em um lado específico.

Na Figura 2, o losango interno de linha sólida representa o diamante doméstico da indústria, enquanto a linha tracejada a sua volta é o diamante internacional, que representa a soma entre o diamante doméstico e as variáveis internacionais. Por essa razão, ele sempre é maior do que o diamante doméstico.

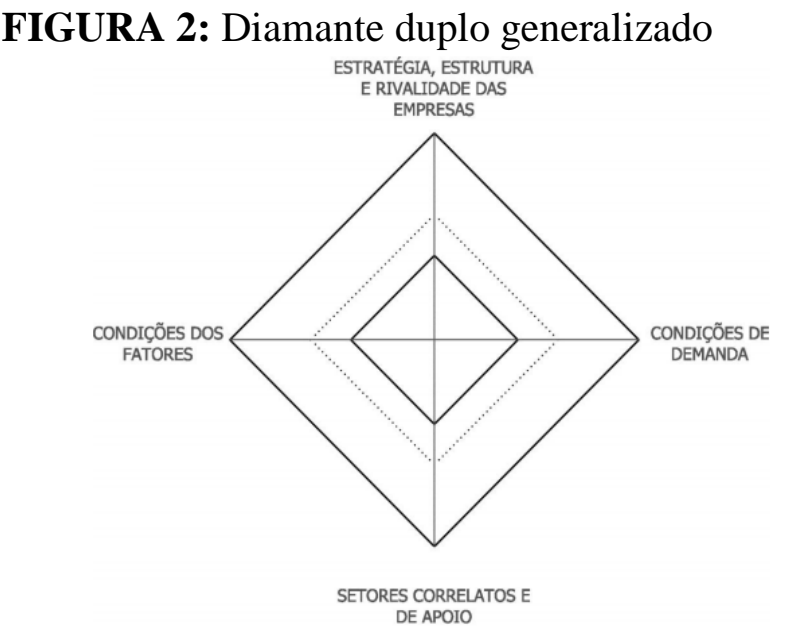

Fonte: Moon, Rugman e Verbeke (1998)

Embora as quatro pontas sejam iguais ao modelo de Porter, nas condições dos fatores ressalta-se a importância do IDE como fonte de acesso às novas tecnologias. Com relação às condições de demanda, é considerada a dependência e a difusão das exportações. Dessa forma, essas duas variáveis podem ajudar a medir a sofisticação e distribuição da demanda enfrentada pelas firmas. Para mensurar impactos internacionais sobre a competitividade com relação às indústrias relacionadas e de apoio, foi incluída a análise dos portos como principal via do comércio internacional. O último determinante do diamante incorporou a abertura comercial do país e seu market share, fatores considerados fundamentais como indicadores de competitividade nacional (CHO; MOON, 2013).

O Diamante Duplo Generalizado é um modelo empírico de análise relativa, ou seja, necessita de dois países para que possa ser construído. O resultado final - tamanho dos diamantes mostra a competitividade de um país, região ou setor em relação a outro no mercado internacional e, quanto maior o diamante, maior a competitividade. 


\section{A Indústria Eletrônica: contexto mundial}

O setor eletroeletrônico é bastante dinâmico e inovador e permeia várias atividades produtivas, surgindo na base de outros setores econômicos, como no controle de processos produtivos, em bens de capital, atividades agropecuárias, comércio, serviços de saúde, mercado financeiro, projetos de engenharia, mecânica, entre outros. ${ }^{1}$ Os avanços tecnológicos da indústria eletrônica, como a microeletrônica, aceleraram o ritmo de inovações além do complexo eletrônico, de modo que as empresas do setor se tornaram líderes do novo padrão tecnológico que alguns chamam de Terceira Revolução Industrial. Além disso, ao longo dos anos, economias mais especializadas em produtos eletrônicos tenderam a apresentar maior taxa de crescimento do produto interno bruto (PIB) (ANSANELLI, 2011).

A indústria eletrônica nasceu no fim do século XIX e início do XX, mas se consolidou após a Segunda Guerra Mundial nos países da tríade. A partir dos anos 1960, as economias asiáticas, como Japão e Coreia do Sul, ascenderam no cenário mundial. Nos anos 1980, com a desregulamentação dos mercados, intensificaram-se os fluxos de Investimento Direto Estrangeiro (IDE) para mercados emergentes e aumentou a inserção internacional da indústria. Em parte, por isso, foi sendo formado um tipo de rede de produção global, que concentrou atividades de maior valor agregado nas unidades constituintes da corporação e passou a subcontratar a produção em outras localizações (GOUVEIA, 2004; SÁ, 2004).

Nos anos 1990 e 2000, como mostra o Gráfico 1, a indústria eletrônica mundial cresceu 7\% ao ano, em média, superando o crescimento de outras indústrias de transformação, como aeroespacial e automotiva, e o PIB mundial. Tal ascensão resulta do elevado investimento realizado por empresas de diversas áreas no setor. Apenas no ano de 2007, 29\% dos investimentos em pesquisa e desenvolvimento (P\&D) realizados pelas empresas foram direcionados para bens eletrônicos (JARUZELSKI; DEHOFF, 2008).

GRÁFICO 1. Crescimento médio anual da produção de equipamentos eletrônicos e outras atividades industriais entre 1996 e 2006 (em \%)

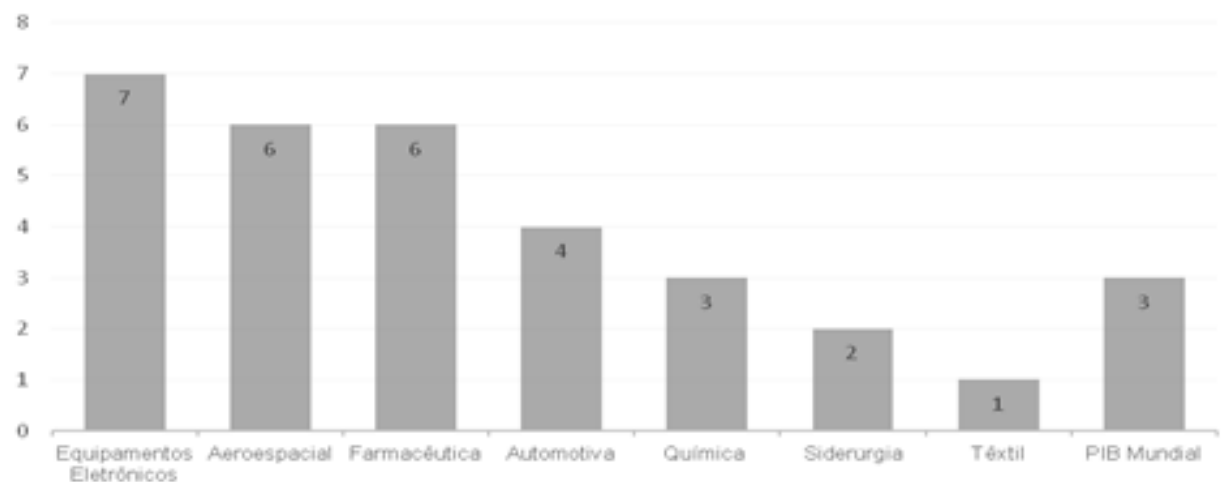

Fonte: Bampi (2009)

No Quadro 1 abaixo, apresenta-se a evolução dos principais países exportadores ao longo dos últimos anos. A principal mudança foi o crescimento e domínio dos chineses que, em 20 anos, se consolidaram como líderes no mercado mundial. Enquanto em 1992 a participação de suas exportações nas exportações mundiais era menor do que 3\%, em 2014 sua fatia correspondeu a uma porcentagem maior do que a soma dos outros quatro maiores países.

\footnotetext{
${ }^{1}$ O complexo eletrônico, segundo a definição usada pelo Banco Nacional de Desenvolvimento Econômico e Social (BNDES), envolve os segmentos de componentes; informática e automação industrial; equipamentos de telecomunicações e eletrônica de consumo. Sua característica fundamental é a produção de bens de mesma base tecnológica (microeletrônica).
} 
QUADRO 1. Participação das exportações de eletrônicos de países selecionados nas exportações mundiais (em \%)

\begin{tabular}{|c|c|c|c|c|c|}
\hline \multicolumn{2}{|c|}{1992} & \multicolumn{2}{c|}{2002} & \multicolumn{2}{c|}{2014} \\
\hline Japão & $25,97 \%$ & China & $14,12 \%$ & China & $37,57 \%$ \\
\hline EUA & $18,81 \%$ & EUA & $12,36 \%$ & EUA & $7,94 \%$ \\
\hline Alemanha & $14,16 \%$ & Japão & $10,07 \%$ & Alemanha & $6,79 \%$ \\
\hline Coreia do Sul & $6,21 \%$ & Alemanha & $7,77 \%$ & Coreia do Sul & $6,35 \%$ \\
\hline Cingapura & $5,77 \%$ & Cingapura & $5,23 \%$ & Cingapura & $5,76 \%$ \\
\hline Brasil & $0,40 \%$ & Brasil & $0,35 \%$ & Brasil & $0,20 \%$ \\
\hline
\end{tabular}

Fonte: Elaboração própria a partir de dados do COMTRADE (2015)

No começo da ascensão chinesa, o que mais atraía as empresas era de fato o câmbio desvalorizado e a exploração exacerbada da mão de obra em níveis que são ilegais em países desenvolvidos. Atualmente, embora ainda importantes, esses motivos tornaram-se secundários. O real valor em produzir lá é que praticamente a cadeia de suprimentos inteira se encontra instalada no país, proporcionando economias de escala e eficiência logística. Na medida em que se concentraram mais empresas na China, ficou mais interessante produzir lá (DUHIGG; BRADSHER, 2012).

\subsection{Cenário Recente da Indústria Eletrônica no Brasil}

O cenário do setor no Brasil tem sido preocupante, conforme mostra a Tabela 1. Nos últimos sete anos as exportações caíram aproximadamente $42,67 \%$, em parte por causa da ascensão dos chineses no mercado mundial. A participação das exportações de eletrônicos no total exportado pelo Brasil, que já era baixa, caiu pela metade. Apesar da queda das importações, o déficit comercial, que sempre existiu, se acentuou em 2013 e 2014, alcançando US\$ 30 bilhões.

TABELA 1. Indicadores da indústria eletrônica no Brasil entre 2008 e 2015

\begin{tabular}{cccccccc}
\hline Indicadores/Ano & $\mathbf{2 0 0 8}$ & $\mathbf{2 0 0 9}$ & $\mathbf{2 0 1 0}$ & $\mathbf{2 0 1 1}$ & $\mathbf{2 0 1 2}$ & $\mathbf{2 0 1 3}$ & $\mathbf{2 0 1 4}$ \\
\hline Faturamento (R\$, bi) & 84,48 & 78,28 & 84,62 & 93,12 & 97,89 & 107,45 & 102,67 \\
Exportações (US\$, bi) & 7,50 & 5,54 & 5,65 & 5,84 & 5,52 & 4,98 & 4,30 \\
$\quad \begin{array}{c}\text { Importações (US\$, bi) } \\
\text { Saldo da balança comercial }\end{array}$ & 27,96 & 21,57 & 29,94 & 34,28 & 34,17 & 36,68 & 35,14 \\
$\quad$ (US\$, bi) & $-20,46$ & $-16,03$ & $-24,29$ & $-28,44$ & $-28,65$ & $-31,70$ & $-30,84$ \\
$\quad \begin{array}{c}\text { Exportações setor/total } \\
\text { exportações do país }\end{array}$ & $4 \%$ & $4 \%$ & $3 \%$ & $2 \%$ & $2 \%$ & $2 \%$ & $2 \%$ \\
Importações setor/total & & & & & & & \\
$\quad$ importações do país & $16 \%$ & $17 \%$ & $16 \%$ & $15 \%$ & $15 \%$ & $15 \%$ & $15 \%$ \\
$\quad$ Faturamento/PIB & $3 \%$ & $2 \%$ & $2 \%$ & $2 \%$ & $2 \%$ & $2 \%$ & $2 \%$ \\
\hline
\end{tabular}

Fonte: ABINEE (2015)

Com relação aos segmentos que compõem o complexo eletrônico, como apresentado nas Tabelas 2 e 3, embora todos tenham déficits, o de automação industrial apresentou um aumento significativo de 43\% em suas exportações ${ }^{2}$. Segundo Bampi (2009), esse fato pode ser atribuído ao aumento de demanda associado à tendência de novos equipamentos incorporados nas linhas de produção e aos investimentos que vêm sendo feitos em plantas industriais.

No entanto, o elevado déficit no segmento de componentes - o de maior incorporação de valor agregado - é alarmante. Durante os últimos anos houve uma redução no valor exportado e um aumento explosivo das importações. As importações concentraram-se nesse segmento, porque ele representa o elo mais fraco da cadeia produtiva da indústria eletrônica. Isso dificulta o

\footnotetext{
${ }^{2}$ A classificação do setor, para os propósitos deste trabalho, segue a segmentação da Associação Brasileira da Indústria Eletroeletrônica (ABINEE): (i) componentes eletrônicos (ii) bens de informática (iii) bens de automação industrial (iv) equipamentos de telecomunicações e (v) eletrônica de consumo e utilidades domésticas.
} 
desenvolvimento da indústria nacional, já que os componentes são insumos básicos para grande quantidade de produtos finais.

TABELA 2. Exportações dos segmentos da indústria eletrônica brasileira (em US\$ bilhões)

\begin{tabular}{|c|c|c|c|c|c|c|c|}
\hline Segmento/Ano & 2008 & 2009 & 2010 & 2011 & 2012 & 2013 & 2014 \\
\hline Automação Industrial & 0,39 & 0,34 & 0,41 & 0,54 & 0,55 & 0,54 & 0,56 \\
\hline Componentes Eletrônicos & 3,58 & 2,71 & 3,03 & 3,53 & 3,66 & 3,28 & 2,88 \\
\hline Informática & 0,39 & 0,41 & 0,41 & 0,42 & 0,38 & 0,39 & 0,30 \\
\hline Telecomunicações & 2,36 & 1,60 & 1,25 & 0,89 & 0,57 & 0,43 & 0,26 \\
\hline Utilidades Domésticas & 0,78 & 0,47 & 0,56 & 0,46 & 0,37 & 0,34 & 0,29 \\
\hline
\end{tabular}

Fonte: ABINEE (2015)

TABELA 3. Importações dos segmentos da indústria eletrônica brasileira (em US\$ bilhões)

\begin{tabular}{cccccccc}
\hline Segmentos/Ano & $\mathbf{2 0 0 8}$ & $\mathbf{2 0 0 9}$ & $\mathbf{2 0 1 0}$ & $\mathbf{2 0 1 1}$ & $\mathbf{2 0 1 2}$ & $\mathbf{2 0 1 3}$ & $\mathbf{2 0 1 4}$ \\
\cline { 2 - 8 } Automação Industrial & 2,95 & 2,62 & 3,28 & 3,88 & 3,94 & 4,41 & 4,14 \\
Componentes Eletrônicos & 18,38 & 13,64 & 19,37 & 21,61 & 22,32 & 24,57 & 23,80 \\
Informática & 2,52 & 2,13 & 2,99 & 3,38 & 3,20 & 2,78 & 2,46 \\
Telecomunicações & 2,66 & 2,00 & 2,42 & 3,33 & 2,71 & 2,88 & 2,85 \\
Utilidades Domésticas & 1,45 & 1,18 & 1,88 & 2,08 & 2,01 & 2,05 & 1,88 \\
\hline Fonte: ABINEE & & & & & & &
\end{tabular}

O segmento de informática, embora tenha apresentado queda nas exportações, possui o maior faturamento da indústria e talvez seja um dos mais dinâmicos dentro do complexo eletrônico. Esse desempenho pode ser atribuído ao crescimento do consumo de produtos de informática por classes sociais de menor poder aquisitivo. Os dois outros segmentos também foram importantes em termos de faturamento. $\mathrm{O}$ de telecomunicações refere-se às mudanças em termos de serviços como telefonia fixa, móvel, televisão e internet, estimulando as empresas a investirem mais em modernização e tecnologias novas para conseguirem concorrer no mercado. Já no de utilidades domésticas, grande parte da produção tem sido destinada ao mercado interno, como é visível pela baixa participação das exportações.

\subsection{Cenário Recente da Indústria Eletrônica na China}

O crescimento agressivo da participação chinesa no mercado tornou a indústria eletrônica um elemento fundamental do crescimento econômico chinês. De acordo com APCO WORLDWIDE, o Ministério de Indústria e Tecnologia Informática (MIIT) da China (2009), a indústria eletrônica foi responsável, em média, por $10 \%$ do crescimento anual do PIB entre os anos de 2003-2009. Além disso, entre 2001 e 2007 a média anual da taxa de crescimento das vendas foi de 28\%. E, na década passada, o comércio da indústria (soma das importações e exportações) constituiu mais de 30\% do comércio internacional da China. Em 2008, o comércio de eletrônicos somava USD \$885,43 bilhões, aproximadamente 34,6\% do valor total do comércio internacional chinês (APCO WORLDWIDE, 2009).

O Quadro 2 mostra os principais produtos importados e exportados pela indústria eletrônica chinesa em 2008. Circuito integrado foi a categoria de maior importação, enquanto computadores portáteis, os produtos mais exportados. 
QUADRO 2: Principais produtos exportados e importados pela China em 2008 (em US\$ bilhões)

\begin{tabular}{|c|c|c|c|c|c|}
\hline \multicolumn{3}{|c|}{ Produtos mais importados } & \multicolumn{3}{c|}{ Produtos mais exportados } \\
\hline $\mathrm{N}^{\mathrm{o}}$ & Produto & Valor Importado & $\mathrm{N}^{\circ}$ & Produto & Valor Exportado \\
\hline $1^{\mathrm{o}}$ & Circuito Integrado & 129,3 & $1^{\mathrm{o}}$ & Computador Portátil & 65,6 \\
\hline $2^{\mathrm{o}}$ & Painel LCD & 44,1 & $2^{\circ}$ & Celular & 38,5 \\
\hline $3^{\mathrm{o}}$ & Disco Rígido & 12,2 & $3^{\circ}$ & Circuito Integrado & 24,3 \\
\hline $4^{\mathrm{o}}$ & Circuito Impresso & 11,1 & $4^{\circ}$ & Painel LCD & 22,4 \\
\hline $5^{\circ}$ & Acessório de Celular & 9,5 & $5^{\circ}$ & Acessório de Celular & 18 \\
\hline
\end{tabular}

Fonte: APCO WORLDWIDE (2009)

Os valores de importações podem parecer elevados, mas a taxa de crescimento das importações caiu de um valor entre 50\% e 60\% em 2003 para menos de $10 \%$ em 2008. Essa queda na taxa de crescimento das importações é decorrente do grande crescimento da indústria eletrônica doméstica. Os principais fatores que contribuíram para o crescimento foram uma mistura de forte apoio governamental, demanda doméstica e internacional elevada e um clima empresarial propício para atrair investimentos e tecnologias. O governo chinês categorizou a indústria eletrônica como estratégica e implementou um plano de quatro anos para tornar os bens de consumo eletrônicos acessíveis nas regiões mais pobres do país, incentivando cidades a estabelecerem parques industriais e oferecendo auxílio financeiro para pesquisa e desenvolvimento nessas empresas (APCO WORLDWIDE, 2009).

Dentre os principais segmentos da indústria eletrônica chinesa, vale destacar três: eletrônica de consumo, semicondutores e painéis de display. O desenvolvimento de tecnologias para aparelhos domésticos, portáteis e automotivos impulsionou o crescimento da eletrônica de consumo. No ano de 2007 , cerca de $30 \%$ da produção mundial total de eletrônica de consumo veio da China. Com relação à origem do capital, apesar da forte presença de multinacionais, tem aumentado a presença de empresas nacionais no segmento e espera-se que se tornem competitivas. No entanto, o domínio das tecnologias mais avançadas ainda está nas mãos de firmas internacionais e constitui uma barreira a ser superada com altos investimentos em P\&D (APCO WORLDWIDE, 2009).

No setor de semicondutores, as firmas chinesas têm enfrentado elevada demanda por circuitos integrados, de modo que $80 \%$ desses produtos usados na produção nacional têm sido importados. Em valor, as importações desses produtos chegaram a US\$129,3 bilhões em 2008. A barreira tecnológica vem sendo um dos maiores obstáculos para melhor desempenho das firmas localizadas no país. Na cadeia de produção do circuito, o elo mais fraco está ligado ao design do produto, seguido pelo próprio processo de produção (APCO WORLDWIDE, 2009).

O segmento de painéis de display encontra-se ainda na fase inicial de desenvolvimento devido à falta de escala, capacidade de realizar P\&D e integração na cadeia de suprimentos. Dentre os produtos desse segmento, a China possui capacidade desenvolvida apenas em Liquid Crystal Display (LCD). O foco nesse produto é fruto de políticas implementadas pelo governo em 2003. O Quadro 2 sugere que a medida foi eficaz, pois LCD foi o quarto produto mais exportado em 2008. Em 2005, 4\% da produção mundial de painéis LCDs vieram da China (APCO WORLDWIDE, 2009).

Dessa maneira, é nítida a diferença entre a indústria eletrônica brasileira e a chinesa. No Brasil, a indústria atua quase que exclusivamente como uma plataforma de montagem. Em determinados segmentos, a China também é uma simples plataforma de montagem, mas em outros é capaz de desenvolver novas tecnologias. Como resultado, a indústria eletrônica potencializou o 
crescimento econômico chinês, enquanto que no Brasil a indústria não consegue se livrar de seus déficits estruturais e nem desenvolver um dinamismo forte com outras indústrias.

\section{Metodologia}

Para mensurar a competitividades da indústria eletrônica no Brasil e na China, por meio do Diamante Duplo Generalizado, e para estimar as estratégias competitivas, foi necessário seguir as seguintes etapas:

$1^{\text {a }}$ Definição e seleção dos indicadores:

Os indicadores utilizados foram escolhidos com base em Cho e Moon (2013). No total são dezoito indicadores, dos quais nove são setoriais, que refletem condições específicas do setor eletrônico, e nove nacionais, transmitindo informações gerais do país que afetam a indústria em questão. O Quadro 3 abaixo apresenta os indicadores, a fonte utilizada e se o indicador representa uma variável nacional ou setorial. Alguns indicadores merecem comentários. O segundo indicador visa mensurar a produtividade dos trabalhadores e o terceiro mostra quanto do trabalho do setor foi dedicado a P\&D. A difusão das exportações, décimo primeiro indicador, resultou das exportações do setor subtraídas dos três principais destinos, dividida pelo total de exportações do setor. Quanto maior esse valor, mais diversificada é a demanda internacional. A densidade rodoviária reflete o tamanho da rede rodoviária em relação ao território do país e a qualidade dos portos é um dado oferecido diretamente pelo Banco Mundial. O cálculo dos indicadores referentes às exportações setoriais resultou da agregação de códigos de produtos do Sistema Harmonizado (HS) que representam o setor e estão no Anexo 1.

O ano de 2011 foi selecionado por ser o mais recente em disponibilidade dos dados, mas alguns dados não estavam acessíveis para alguns indicadores. Nesses casos, utilizou-se o ano mais próximo. 
QUADRO 3: Indicadores utilizados e fonte de pesquisa

\begin{tabular}{|c|c|c|c|c|}
\hline \multicolumn{2}{|c|}{ Determinante do Diamante } & Indicador & Fonte & Tipo \\
\hline \multirow{4}{*}{$\begin{array}{l}\text { Condições } \\
\text { dos Fatores } \\
\text { Domésticos }\end{array}$} & \multirow{2}{*}{ Básico } & 1. PEA (15 Anos) /Total, em \% (2011) & $\begin{array}{l}\text { Banco } \\
\text { Mundial }\end{array}$ & Nacional \\
\hline & & 2. PIB por pessoa empregada, em USD (2011) & $\begin{array}{c}\text { Banco } \\
\text { Mundial }\end{array}$ & Nacional \\
\hline & \multirow{2}{*}{ Avançado } & $\begin{array}{l}\text { 3. Pesquisadores/1000 trabalhadores (Brasil 2011) } \\
\text { (China 2009) }\end{array}$ & $\begin{array}{c}\text { IBGE } \\
\text { (PINTEC) } \\
- \text { NBS } \\
\end{array}$ & Setorial \\
\hline & & 4. Gasto em P\&D/ PIB, em \% (2011) & $\begin{array}{c}\text { IBGE } \\
\text { (PINTEC) } \\
- \text { NBS } \\
\end{array}$ & Setorial \\
\hline \multirow{3}{*}{$\begin{array}{c}\text { Condições } \\
\text { dos Fatores } \\
\text { Internacionais }\end{array}$} & \multirow{2}{*}{ Básico } & 5. Exportação per capita (Brasil 2011) (China 2009) & $\begin{array}{c}\text { UN } \\
\text { Comtrade }\end{array}$ & Setorial \\
\hline & & 6. Depósito de patentes / milhão de habitantes (2011) & $\begin{array}{l}\text { INPI - } \\
\text { NBS }\end{array}$ & Setorial \\
\hline & Avançado & 7. Ingresso de IED/do PIB, em \% (2013) & $\begin{array}{l}\text { BACEN - } \\
\text { NBS } \\
\end{array}$ & Setorial \\
\hline \multirow{4}{*}{$\begin{array}{l}\text { Condições de } \\
\text { Demanda }\end{array}$} & \multirow{2}{*}{ Doméstico } & 8. PIB real per capita (USD, ano base 2000) (2011) & $\begin{array}{c}\text { Banco } \\
\text { Mundial }\end{array}$ & Nacional \\
\hline & & $\begin{array}{l}\text { 9. Graduados no ensino superior/população, em \% } \\
\text { (2011) }\end{array}$ & $\begin{array}{l}\text { MEC - } \\
\text { NBS }\end{array}$ & Nacional \\
\hline & \multirow{2}{*}{ Internacional } & $\begin{array}{l}\text { 10. Dependência das exportações: exportações/PIB, } \\
\text { em \% do (2011) }\end{array}$ & $\begin{array}{c}\text { UN } \\
\text { Comtrade }\end{array}$ & Setorial \\
\hline & & 11. Difusão das exportações, em \% (2011) & $\begin{array}{c}\text { UN } \\
\text { Comtrade } \\
\end{array}$ & Setorial \\
\hline \multirow{3}{*}{$\begin{array}{l}\text { Indústrias } \\
\text { Relacionadas } \\
\text { e de Apoio }\end{array}$} & \multirow{2}{*}{ Doméstico } & $\begin{array}{l}\text { 12. Crédito doméstico oferecido ao mercado nacional } \\
\text { via mercado financeiro nacional, em \% (2011) }\end{array}$ & $\begin{array}{l}\text { Banco } \\
\text { Mundial }\end{array}$ & Nacional \\
\hline & & 13. Densidade rodoviária, em \% (2011) & $\begin{array}{l}\text { Banco } \\
\text { Mundial }\end{array}$ & Nacional \\
\hline & Internacional & 14. Qualidade de Infraestrutura dos Portos (2011) & $\begin{array}{l}\text { Banco } \\
\text { Mundial }\end{array}$ & Nacional \\
\hline \multirow{4}{*}{$\begin{array}{l}\text { Estratégia, } \\
\text { Estrutura e } \\
\text { Rivalidade } \\
\text { Entre Firmas }\end{array}$} & \multirow{2}{*}{ Doméstico } & $\begin{array}{l}\text { 15. Salário médio na economia por mês, em USD } \\
\text { (2011) }\end{array}$ & $\begin{array}{c}\text { IBGE } \\
(\mathrm{PME})- \\
\text { NBS }\end{array}$ & Nacional \\
\hline & & 16. Número de empresas no setor (2011) & $\begin{array}{l}\text { IBGE } \\
\text { (PIA) - } \\
\text { NBS }\end{array}$ & Setorial \\
\hline & \multirow[b]{2}{*}{ Internacional } & 17. Abertura comercial - Open Markets Index (2011) & ICC & Nacional \\
\hline & & $\begin{array}{l}\text { 18. Market share de exportações mundiais: } \\
\text { exportações setor/exportações totais, em \% (2011) }\end{array}$ & $\begin{array}{c}\text { UN } \\
\text { Comtrade }\end{array}$ & Setorial \\
\hline
\end{tabular}

Fonte: Elaboração própria a partir de Cho e Moon (2013)

$2^{\text {a }}$ Coleta e cálculo dos indicadores absolutos e relativos

Como a construção do diamante exige valores relativos - valor dos componentes do setor de um país em relação ao outro - foi realizado o cálculo dos indicadores relativos da seguinte forma: atribuiu-se $100 \%$ para o indicador de maior valor entre os dois países e, para o menor indicador entre os países, utilizou-se a razão em porcentagem, como segue:

$$
\text { Valor Relativo do Indicador do país } \mathrm{A}=\frac{\text { (Indicador mais baixo país A)*100 }}{\text { (Indicador mais alto país B) }}
$$


Onde:

País A é aquele com o menor indicador absoluto

País B é o país com maior indicador absoluto

Esses resultados encontram-se no Quadro 5 na próxima seção.

$3^{\text {a }}$ Construção do gráfico de diamante:

Para a construção do gráfico foram calculados os valores dos quatro determinantes domésticos e internacionais de cada país. Os valores dos fatores domésticos resultam da média dos indicadores relativos de cada componente, enquanto que os valores internacionais são a soma da média dos indicadores domésticos com a média dos indicadores internacionais, conforme equação abaixo:

Valor Determinante Doméstico $=$ média dos valores relativos domésticos

Valor Determinante Internacional $=$ média dos valores relativos doméstic média dos valores relativos dos determinantes internacionais

Tais resultados estão no Quadro 6 e nas Figuras 3 e 4 da próxima seção.

$4^{\mathrm{a}}$ Estimação da melhor estratégia.

A definição da melhor estratégia se compõe por duas partes:

- Estimação da Competitividade sem estratégia: foi feito o cálculo da média aritmética simples dos indicadores relativos domésticos e internacionais para cada um dos quatro grupos de determinantes (condição dos fatores, demanda, indústrias relacionadas e de apoio e estratégia, estrutura e rivalidade). Os valores utilizados estão nas duas últimas colunas do Quadro 4. O índice de competitividade sem estratégia foi obtido pela média desses componentes, cujos resultados encontram-se no Quadro 6 da próxima seção;

- Estimação da Competitividade com estratégia de custo e diferenciação: também foi calculada a média dos indicadores relativos de cada componente, mas a esses foram atribuídos pesos definidos por Cho e Moon (2013) referentes a cada determinante, conforme Quadro 4 abaixo. Como em uma estratégia de custo, por exemplo, as condições de fatores são fundamentais; esse determinante recebeu um peso maior, enquanto que a diferenciação importa mais para a demanda. Após o cálculo das médias com os pesos, foram fornecidos dois índices adicionais, um para custo e outro para diferenciação: o de maior valor mostra qual estratégia poderia elevar o desempenho brasileiro no mercado mundial tomando como parâmetro a indústria eletrônica chinesa. Os resultados estão no Quadro 7 da próxima seção.

QUADRO 4: Pesos para as estratégias

\begin{tabular}{|c|c|c|}
\hline & Custo & Diferenciação \\
\hline Condições dos Fatores & $44 \%$ & $12 \%$ \\
\hline Condições de Demanda & $12 \%$ & $44 \%$ \\
\hline Indústrias Relacionadas e de Apoio & $12 \%$ & $32 \%$ \\
\hline Estratégia, Estrutura e Rivalidade Entre Firmas & $32 \%$ & $12 \%$ \\
\hline
\end{tabular}

Fonte: Cho e Moon (2013)

\section{Resultados}

O Quadro 5 abaixo oferece os valores dos indicadores em termos absolutos e relativos. Deve-se observar que os indicadores maiores do Brasil em relação à China têm como razão o tamanho da população e não refletem necessariamente uma vantagem do país, como PIB real per capita e graduados no ensino superior. O salário médio chinês é inferior ao nacional, provavelmente, pelo baixo custo da mão de obra chinesa. 
QUADRO 5: Valores absolutos e relativos dos indicadores

\begin{tabular}{|c|c|c|c|c|c|c|}
\hline \multirow{2}{*}{\multicolumn{2}{|c|}{ Determinante do Diamante }} & \multirow[b]{2}{*}{ Indicador } & \multicolumn{2}{|c|}{ Valores Absolutos } & \multicolumn{2}{|c|}{$\begin{array}{c}\text { Valores } \\
\text { Relativos (em } \\
\%) \\
\end{array}$} \\
\hline & & & Brasil & China & Brasil & China \\
\hline \multirow{4}{*}{$\begin{array}{l}\text { Condições } \\
\text { dos Fatores } \\
\text { Domésticos }\end{array}$} & \multirow[b]{2}{*}{ Básico } & PEA (15 Anos) / Total, em \% & $53,34 \%$ & $59,21 \%$ & 90,08 & 100,00 \\
\hline & & $\begin{array}{c}\text { PIB por pessoa empregada, em } \\
\text { USD }\end{array}$ & 13592 & 14203 & 95,70 & 100,00 \\
\hline & \multirow{2}{*}{ Avançado } & Pesquisadores/1000 trabalhadores & 50 & 48 & 100,00 & 95,62 \\
\hline & & Gasto em P\&D/ PIB, em \% & $0,07 \%$ & $0,39 \%$ & 18,69 & 100,00 \\
\hline \multirow{3}{*}{$\begin{array}{c}\text { Condições } \\
\text { dos Fatores } \\
\text { Internacionais }\end{array}$} & \multirow[b]{2}{*}{ Básico } & Exportação per capita & 1434,98 & 36252,42 & 3,96 & 100,00 \\
\hline & & $\begin{array}{c}\text { Depósito de patentes / milhão de } \\
\text { habitantes }\end{array}$ & 16,63 & 53,48 & 31,10 & 100,00 \\
\hline & Avançado & Ingresso de IED/do PIB, em \% & $0,05 \%$ & $0,64 \%$ & 8,48 & 100,00 \\
\hline \multirow{4}{*}{$\begin{array}{l}\text { Condições de } \\
\text { Demanda }\end{array}$} & \multirow[b]{2}{*}{ Doméstico } & PIB real per capita, em USD & 5848,98 & 3150,00 & 100,00 & 53,86 \\
\hline & & $\begin{array}{c}\text { Graduados no ensino } \\
\text { superior/população, em \% }\end{array}$ & $0,51 \%$ & $0,45 \%$ & 100,00 & 89,23 \\
\hline & \multirow[t]{2}{*}{ Internacional } & $\begin{array}{l}\text { Dependência das exportações: } \\
\text { exportações/PIB, em \% }\end{array}$ & $0,02 \%$ & $4,48 \%$ & 0,43 & 100,00 \\
\hline & & Difusão das exportações, em \% & $47,62 \%$ & $66,48 \%$ & 71,63 & 100,00 \\
\hline \multirow{3}{*}{$\begin{array}{l}\text { Indústrias } \\
\text { Relacionadas } \\
\text { e de Apoio }\end{array}$} & \multirow[t]{2}{*}{ Doméstico } & $\begin{array}{l}\text { Crédito doméstico oferecido ao } \\
\text { mercado nacional via mercado } \\
\text { financeiro nacional, em } \%\end{array}$ & $95,20 \%$ & $142,10 \%$ & 67,00 & 100,00 \\
\hline & & Densidade rodoviária, em \% & $18,60 \%$ & $42,77 \%$ & 43,49 & 100,00 \\
\hline & Internacional & $\begin{array}{c}\text { Qualidade de Infraestrutura dos } \\
\text { Portos }\end{array}$ & 2,7 & 4,5 & 60,00 & 100,00 \\
\hline \multirow{4}{*}{$\begin{array}{l}\text { Estratégia, } \\
\text { Estrutura e } \\
\text { Rivalidade } \\
\text { Entre Firmas }\end{array}$} & \multirow[t]{2}{*}{ Doméstico } & $\begin{array}{c}\text { Salário médio na economia por } \\
\text { mês, em USD }\end{array}$ & 1051,62 & 463,88 & 100,00 & 44,11 \\
\hline & & Número de empresas no setor & 3097 & 11364 & 27,25 & 100,00 \\
\hline & \multirow[b]{2}{*}{ Internacional } & $\begin{array}{c}\text { Abertura comercial - Open } \\
\text { Markets Index }\end{array}$ & 2,3 & 2,8 & 82,14 & 100,00 \\
\hline & & $\begin{array}{l}\text { Market share de exportações } \\
\text { mundiais: exportações } \\
\text { setor/exportações totais, em \% }\end{array}$ & $0,04 \%$ & $25,37 \%$ & 0,15 & 100,00 \\
\hline
\end{tabular}

Fonte: Elaboração própria

Os valores do gráfico do diamante são apresentados pelo Quadro 6 a seguir. Com relação à competitividade internacional do setor, a China supera o Brasil em todos os componentes. Com relação aos aspectos domésticos, o principal determinante da competitividade nacional é a demanda, o que faz sentido, pois o Brasil é um grande mercado.

QUADRO 6: Dados do diamante doméstico e internacional da indústria eletrônica no Brasil e na China

\begin{tabular}{|c|c|c|c|c|}
\hline & \multicolumn{2}{|c|}{ Brasil } & \multicolumn{2}{c|}{ China } \\
\hline Determinantes & Doméstico & Internacional & Doméstico & Internacional \\
\hline 1. Condições dos Fatores & $76,12 \%$ & $90,63 \%$ & $98,91 \%$ & $198,91 \%$ \\
\hline 2.Condições de Demanda & $100,00 \%$ & $136,03 \%$ & $71,54 \%$ & $171,54 \%$ \\
\hline 3. Indústrias Relacionadas e de Apoio & $55,24 \%$ & $115,24 \%$ & $100,00 \%$ & $200,00 \%$ \\
\hline
\end{tabular}


Os gráficos da Figura 3 e 4 são a representação visual desses indicadores. É importante observar os valores de cada ponta do diamante no quadro acima, porque, embora o diamante doméstico do setor brasileiro pareça maior que o da China, ele é menor em termos absolutos.

A competitividade internacional da China é bastante superior à doméstica e as variáveis internacionais são significativas em todas as pontas do diamante. Essa diferença elevada de tamanho entre o diamante doméstico e o internacional corrobora as críticas de Cho e Moon (2013) sobre Porter (1990), quando afirmaram que o diamante doméstico não necessariamente precisaria ser grande para o país (ou indústria) se tornar competitivo.

O Brasil, por sua vez, não só é menos competitivo internacionalmente na indústria eletrônica, como a incorporação das variáveis internacionais afetam muito pouco as pontas 1, 2 e 4 . A ponta 1, condição dos fatores, é a menor do diamante brasileiro e possivelmente um dos principais motivos que explicam a baixa competitividade internacional do setor. Faz sentido, uma vez que o Brasil não possui uma mão de obra barata nem qualificada quando comparado a outros países. Assim, os determinantes domésticos possuem um peso muito maior para a competitividade brasileira.

FIGURA 3: Diamante duplo generalizado da indústria eletrônica chinesa

Fonte: Elaboração própria

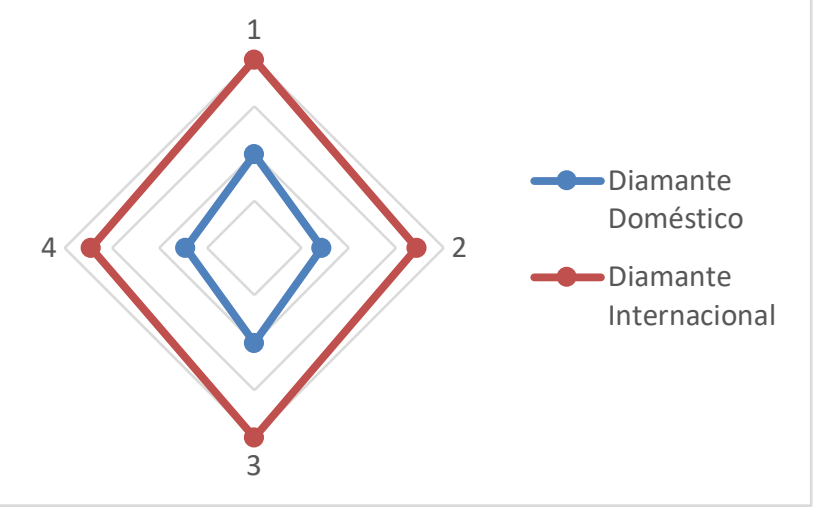

FIGURA 4: Diamante duplo generalizado da indústria eletrônica brasileira

Fonte: Elaboração própria

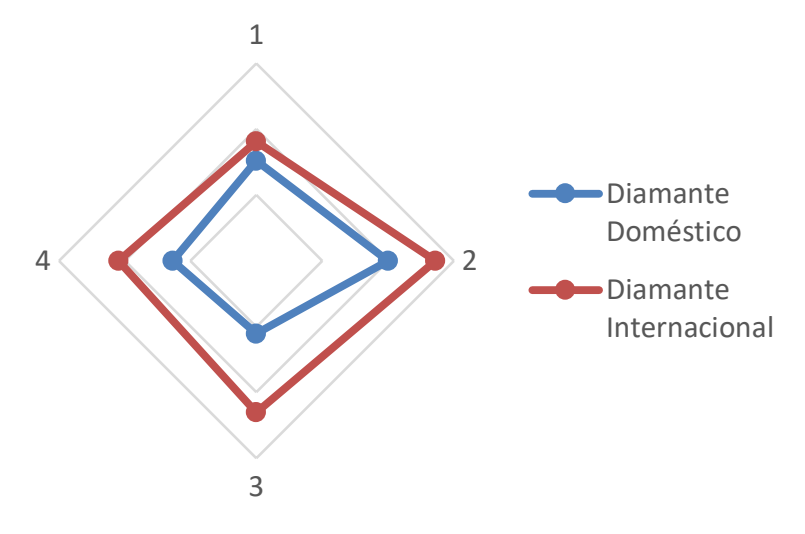




\subsection{Estimando a Melhor Estratégia}

Os Quadros 7 e 8 abaixo nos respondem qual seria a melhor direção para a indústria brasileira tendo como referência a chinesa. Sem adotar estratégia, o índice de competitividade da indústria é 56,74\%; com uma estratégia de custo, ele cai para 53,62\%, mas sobe para 60,36\% se o setor adotar uma estratégia de diferenciação. A China, adotando uma estratégia de custo, tem um indicador de 93,54\%, que é superior à competitividade sem estratégia ou de diferenciação e reflete a condição real do país.

QUADRO 7: Média dos valores relativos e índice de competitividade sem estratégia

Fonte: Elaboração própria

\begin{tabular}{|c|c|c|}
\hline & Brasil & China \\
\hline Condições dos Fatores & $49,72 \%$ & $99,37 \%$ \\
\hline Condições de Demanda & $68,01 \%$ & $85,77 \%$ \\
\hline Indústrias Relacionadas e de Apoio & $56,83 \%$ & $100,00 \%$ \\
\hline Estratégia, Estrutura e Rivalidade Entre Firmas & $52,39 \%$ & $86,03 \%$ \\
\hline Competitividade Sem Estratégia & $\mathbf{5 6 , 7 4 \%}$ & $\mathbf{9 2 , 7 9 \%}$ \\
\hline
\end{tabular}

QUADRO 8: Média dos valores relativos e índice de competitividade com estratégia

\begin{tabular}{|c|c|c|c|c|}
\hline & \multicolumn{2}{|c|}{ Brasil } & \multicolumn{2}{c|}{ China } \\
\hline & Custo & Diferenciação & Custo & Diferenciação \\
\hline Condições dos Fatores & $22 \%$ & $6 \%$ & $44 \%$ & $12 \%$ \\
\hline Condições de Demanda & $8 \%$ & $30 \%$ & $10 \%$ & $38 \%$ \\
\hline Indústrias Relacionadas e de Apoio & $7 \%$ & $18 \%$ & $12 \%$ & $32 \%$ \\
\hline Estratégia, Estrutura e Rivalidade Entre Firmas & $17 \%$ & $6 \%$ & $28 \%$ & $10 \%$ \\
\hline Competitividade Com Estratégia & $\mathbf{5 3 , 6 2 \%}$ & $\mathbf{6 0 , 3 6 \%}$ & $\mathbf{9 3 , 5 4 \%}$ & $\mathbf{9 1 , 9 9 \%}$ \\
\hline
\end{tabular}

Fonte: Elaboração própria

Portanto, ao adotar uma estratégia de diferenciação, a indústria eletrônica brasileira poderia se tornar mais competitiva tomando como referência a indústria chinesa no mercado mundial. Isso faz sentido, visto que seria extremamente difícil competir com a escala e os baixos custos dos chineses. É válido lembrar que, embora a competitividade aumente cerca de 4\%, esse crescimento pode causar um impacto financeiro significativo por se tratar de um mercado de trilhões de dólares.

\section{Conclusão}

O objetivo desse artigo foi mensurar a competitividade da indústria eletrônica brasileira e chinesa, com o intuito de estimar qual deveria ser a melhor estratégia competitiva da indústria eletrônica nacional tendo como referência a chinesa, devido a seu destaque no mercado internacional. A China apresentou um crescimento excepcional no setor mundial, tornando-se a maior ofertante global. Seu ingresso, embora tenha se dado pela estratégia de custos baixos, atualmente foi capaz de proporcionar economias e escala e eficiência devido à instalação de toda cadeia de suprimentos no país. No sentido oposto, o complexo eletrônico brasileiro amarga déficits crescentes, sobretudo no segmento de componentes eletrônicos - o de maior incorporação de valor agregado. Ressaltou-se que esse segmento está ameaçado de desindustrialização.

A metodologia utilizada para a análise da competitividade, diante desse contexto, foi relativa, ou seja, toma como referência o setor eletrônico chinês. Tendo como ponto de partida o modelo de Porter (1990), que apresentou quatro fatores determinantes da competitividade de uma nação, o método aqui utilizado representou um avanço teórico por incorporar variáveis internacionais essenciais à realidade de países em desenvolvimento, como o IDE. Os resultados da aplicação do modelo, conhecido como Diamante Duplo Generalizado, mostraram que a competitividade internacional chinesa no setor é superior à doméstica, corroborando o referencial 
teórico do modelo. No Brasil, a competitividade do setor é determinada principalmente por fatores domésticos e os elementos internacionais pouco a afetaram. A melhor estratégia estimada para o complexo eletrônico brasileiro foi a diferenciação, pois dessa forma o índice de competitividade do setor aumentaria 4\%, algo bastante significativo num mercado de trilhões de dólares.

Contudo, ao longo do trabalho foram observadas algumas lacunas. A primeira delas seria mensurar o impacto financeiro da adoção de determinadas estratégias na indústria. Outro aspecto que merece ser investigado refere-se aos pesos atribuídos aos determinantes para estimação da melhor estratégia - custo ou diferenciação -, já que os autores do modelo não explicam detalhadamente esses pesos.

\section{Referências bibliográficas}

ABINEE. O PANORAMA ECONÔMICO. São Paulo, 2009. Disponível em: $<$ http://www.funcex.org.br/material/redemercosul_bibliografia/biblioteca/ESTUDOS_BRASIL/BR A_142.pdf>. Acesso em: 08/01/2015.

ABINEE. O PANORAMA ECONÔMICO. São Paulo, 2015. Disponível em:

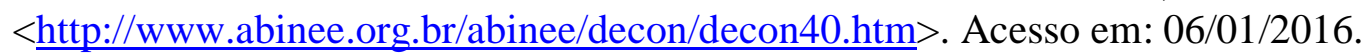

ANSANELLI, S. L. M. Exigências Ambientais Europeias: novos desafios competitivos para o complexo eletrônico brasileiro. Revista Brasileira de Inovação, [S.l.], v. 10, n. 1, p. 129-160, jan./jun., 2011.

APCO WORLDWIDE. MARKET ANALYSIS REPORT: CHINA'S ELECTRONICS INDUSTRY, 2009. Disponível em <http://itrade.gov.il/china-en/files/2012/07/APCO-MarketStudy-for-IEICI-Electronics-For-Embassy-2009.pdf> . Acesso em: 14/11/2015.

BAMPI, S. (Coord.). PERSPECTIVA SOBRE INVESTIMENTO BRASILEIRO: INDÚSTRIA ELETRÔNICA. UNICAMP/UFRJ, 2009. Disponível em: $<$ http://www3.eco.unicamp.br/neit/images/stories/arquivos/ie_ufrj_sp08_eletronica.pdf $>$. Acesso em: 06/01/2014.

BANCO CENTRAL DO BRASIL. FLUXOS DE INVESTIMENTO. Disponível em: $<$ http://www.bcb.gov.br/ftp/notaecon/InvEstrp.xls $>$. Acesso em: 14/11/2015.

BANCO MUNDIAL. THE WORLD BANK INDICATORS [base de dados na Internet]. Disponível em: <http://data.worldbank.org/indicator>. Acesso em: 08/01/2015.

CHO, D.-S.; MOON, H.-C. From Adam Smith to Michael Porter: Evolution of Competitiveness Theory.1. ed. Cingapura: World Scientific Co., 2013.

COMTRADE. UN COMTRADE DATABASE [base de dados na Internet]. Disponível em: $<$ http://comtrade.un.org/>. Acesso em: 08/01/2015.

DECISION. World electronic industries 2008-2013. Executive Summary. Paris: Decision, abr.

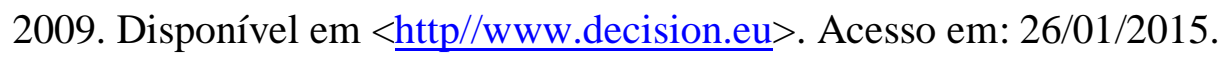

DUHIGG, C.; BRADSHER, K. How the U.S. Lost Out on iPhone Work. The New York Times, jan. 2012. Disponível em: <http://www.nytimes.com/2012/01/22/business/apple-america-and-asqueezed-middle-class.html? r=2\&ref=charlesduhigg\&pagewanted=all $>$. Acesso em: 14/11/2015.

FOREIGN TRADE ON LINE, 2015. Disponível em: <http://www.foreigntrade.com/reference/hscode.htm>. Acesso em: 14/11/2015.

GOUVEIA, F. O papel das subsidiárias brasileiras na nova configuração das corporações multinacionais: um estudo com base na indústria eletrônica, 2004, 272f. (Dissertação de Mestrado em Ciências Econômicas) Instituto de Economia, Universidade Estadual de Campinas, Campinas.

GUTIERREZ, R. M. V. Complexo Eletrônico: lei de informática e competitividade. BNDES setorial, n. 31, 2010.

IBGE. PESQUISA INDUSTRIAL ANUAL 2011. Rio de Janeiro: IBGE, 2011. Disponível em: <http://biblioteca.ibge.gov.br/visualizacao/periodicos/1719/pia_2011_v30_n1_empresa.pdf>.

Acesso em: 08/01/2015.

IBGE. PESQUISA INDUSTRIAL DE INOVAÇÃO TECNOLÓGICA, 2011. Rio de Janeiro: IBGE, 2013. Disponível em: 
<http://www.pintec.ibge.gov.br/downloads/pintec2011\%20publicacao\%20completa.pdf $>$. Acesso em: 08/01/2015.

IBGE. PESQUISA MENSAL DE EMPREGO. Disponível em: $<\underline{\text { http://www.ibge.gov.br/home/presidencia/noticias/imprensa/ppts/00000013140705132013070224 }}$ 735986.xls >. Acesso em: 06/01/2014.

ICC. OPEN MARKETS INDEX. 2013. Disponível em: <http://www.iccwbo.org/Data/Documents/Global-Influence/G20/Products/2011-Open-MarketsIndex-(OMI)-pdf/>. Acesso em: 06/01/2014.

INPI. DEPÓSITO DE PATENTES. 2013. Disponível em:

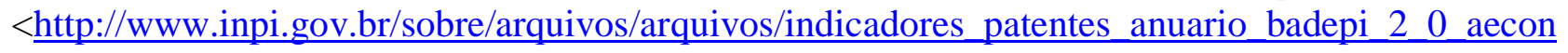
_vf.zip>. Acesso em: 06/01/2014.

JARUZELSKI, B.; DEHOFF, K. Beyond Borders: The Global Innovation 1000. Winter 2008, nov. 2008. Disponível em: <http://www.strategy-business.com/article/08405?gko=87043>. Acesso em: 14/11/2015.

KUPFER, D. Padrões de concorrência e competitividade. In: Encontro Nacional da ANPEC, 20, 1992, São Paulo. Anais... São Paulo, 1992.

MEC. Censo da Educação Superior. 2011. Disponível em: $<$ http://www.abruem.org.br/uploads/foruns/51/palestras/censo.pdf>. Acesso em: 14/11/2015.

MOON, H.-C.; RUGMAN, A. M.; VERBEKE, A. A Generalized Double Diamond Approach to Global Competitiveness of Korea and Singapore. International Business Review, [S.1.], v. 7, p. 135150, abr., 1998.

NATIONAL BUREAU OF STATISTICS OF CHINA [base de dados na Internet]. Disponível em: $<$ http://www.stats.gov.cn/english/Statisticaldata/AnnualData/>. Acesso em: 08/01/2015.

PORTER, M. Competitive Advantage of Nations. 1. ed. New York: The Free Press, 1990.

POSSAS, S. Concorrência e Competitividade: Notas sobre Estratégia e Dinâmica Seletiva na Economia Capitalista. São Paulo: Editora Hucitec, 1999.

RUGMAN, A. M.; D’CRUZ, J. R. The "Double Diamond" Model of International Competitiveness: The Canadian Experience. Management International Review, [S.l.], v. 33, p. 17-39, 1993.

SÁ, M. T. V. A indústria de bens eletrônicos de consumo frente a uma nova rodada de abertura, 2004, 392f. (Tese de Doutorado em Ciências Econômicas) Instituto de Economia, Universidade Estadual de Campinas, Campinas.

ANEXO 1: Lista de Códigos do Sistema Harmonizado de Produtos Eletrônicos
\begin{tabular}{|c|l|}
\hline Código & Produto \\
\hline 8469 & Máquinas de escrever e máquinas processadoras de texto \\
\hline 8470 & Máquinas de cálculo e contabilidade \\
\hline 8471 & Máquinas de processamento automático de dados, hardware de computador, etc. \\
\hline 8473 & Partes e acessórios para máquinas de escrever, computadores e outros \\
\hline 8518 & Microfones, autofalantes, amplificadores de som, etc. \\
\hline 8519 & Tocadores de discos, fitas, etc. \\
\hline 8520 & Gravadores de som \\
\hline 8521 & Equipamentos de gravação e reprodução de vídeo \\
\hline 8522 & Partes e acessórios de tocadores, gravadores, etc. \\
\hline 8525 & Equipamentos de radiotelefonia, câmeras de TV, telefones sem fio \\
\hline 8526 & Equipamento de radar, navegação por rádio e controles remotos \\
\hline 8527 & Equipamentos para recepção de radiotelefonia, etc. \\
\hline 8528 & Receptores de televisão \\
\hline 8529 & Partes para televisões, rádio e radares \\
\hline 8541 & Semicondutores \\
\hline 8542 & Circuitos eletrônicos, etc. \\
\hline
\end{tabular}

Fonte: Foreign Trade (2015). 